\title{
A Quantitative Analysis of System Readiness Level Plus (SRL+): Development of Readiness Level Measurement
}

\author{
Novi Marlyana ${ }^{1,2,}$, , Alva Edy Tontowi $^{1}$, and Hari Agung Yuniarto ${ }^{1}$ \\ ${ }^{l}$ Department of Mechanical and Industrial Engineering, Faculty of Engineering, Universitas Gadjah \\ Mada, Jl. Grafika No.2 Kampus UGM, Yogyakarta, Indonesia, 55281 \\ ${ }^{2}$ Department of Industrial Engineering, Faculty of Industrial Technology, Universitas Islam Sultan \\ Agung, Jl. Raya Kaligawe KM. 4, Semarang, Indonesia, 50221
}

\begin{abstract}
The research explains the development of Readiness Level measurement. The initial concept of Readiness Level is Technology Readiness Level (TRL). TRL is an important metric used by U.S. government agencies such as NASA and the Department of Defense and is designed to quantify the maturity of a new technology and to enable comparisons with alternatives. System technology assessment evolves with the presence of Integration Readiness Level (IRL) and System Readiness Level (SRL). A quantitative combination of levels of readiness can be made and open the potential for expanding the other sizes of readiness levels, such as the Manufacturing Readiness Level (MRL). A measurement tool to measure the development of readiness level by involving MRL is called System Readiness Level Plus (SRL ${ }^{+}$). This research focuses on quantitative analysis of $\mathrm{SRL}^{+}$model. It consists of the mathematical properties method and readiness reversal method. Several steps can be conducted to design the $\mathrm{SRL}^{+}$model. This model was developed from the System Readiness Level metric by Ross, combined with Incidence Matrix Approach by London. The first step is developing the function of the $\mathrm{SRL}^{+}$model. The second step is conducting computation using a development model that is $\mathrm{SRL}^{+}$. The third step is carrying out validity of SRL ${ }^{+}$model. The result indicates that $\mathrm{SRL}^{+}$ model can be mathematically proven.
\end{abstract}

\section{Introduction}

A product starts from a technology before it is introduced to the market. New technologies have more prospects to be accepted in the market because technology is the key to growth [1]. But often in many companies, products with new technology are not necessarily ready to be commercialized. This is because there is no certainty about the readiness of technology when heading to the market. The possibility that happens is the technology ready to be accepted by the market or emerged problems that will lead to waste of time and cost, the

\footnotetext{
*Corresponding author: novi@unissula.ac.id
} 
emergence of consumer dissatisfaction and loss of consumers into the hands of competitors. Technology Readiness Assessment (TRA) is required as part of product development [1].

TRA is needed when an organization tries to determine the maturity of new technologies and / or capabilities (including technical or economic performance levels required) [2,3]. This method is applied in many domains such as military system [3], defense acquisition, aeronautics and astronautics and energy resources [4], and automotive industry [5]. The Technology Readiness Level (TRL) method is widely used for TRA [4]. TRL is used to measure the readiness of equipment (hardware) $[1,2,4,6]$.

TRL is an important measure used by US Government agencies such as NASA and the Department of Defense and is designed to measure maturity of new technologies and enable comparison of alternatives. TRL has proven useful in identifying whether new components developed in technology programs are ready to operate as mature products. The TRL scale starts from 1 (basic principles observed) and ends at 9 (mission / proven activities) [1,2,4,6,7]. Furthermore, to evaluate the interconnection of components within a complex system, it is used Integration Readiness Level (IRL) [8].

The System Readiness Level (SRL) was developed to evaluate whole-system development risk and to support program acquisition decisions. SRLs mathematically combined component TRL values with system integration IRL and created a separate measure of system technical progress [8-10]. The underlying motivation of SRL was that complex systems and System-of-Systems (SoSs) require a more robust readiness assessment than TRL component evaluations alone could provide. SRL values are measured for individual components (both technology components/TRL and integration elements/IRL) and these subsystem component values produced a comprehensive system level SRL value.

A quantitative combination of readiness levels can be made and opens the potential for expanding the SRL by integrating other measurement of readiness levels, such as the Manufacturing Readiness Level (MRL) [8]. A measurement tool to measure the development of readiness level by involving MRL is called System Readiness Level Plus $\left(\mathrm{SRL}^{+}\right)$. This tool was developed from the System Readiness Level metric by [11], combined with Incidence Matrix Approach by $[9,10]$. The three TRA components described at the product level illustrate the relationship between individual components $[9,10]$, then on measurement of technology at the company level will involve the readiness of the technology of its manufacturing technologies known as Manufacturing Readiness Level (MRL) [5]. A combination of TRL, IRL, and MRL was improved by [11]. The combination was developed from the previous concepts of the System and Integration Readiness Level by Sauser [3,811], combined with the concepts of Technology, Integration, and Manufacturing Readiness Levels, into a single metric-System Readiness Level. In the Sauser formula, TRL value and IRL value are multiplied to form an SRL value [8,11].

This research will emphasize on proving mathematical model $\mathrm{SRL}^{+}$through quantitative analysis of the mathematical model of $\mathrm{SRL}^{+}$by using mathematical properties method $[9,12]$ and readiness reversal method $[9,10]$. The purpose of performing quantitative analysis is to increase the validity of the calculation of $\mathrm{SRL}^{+}$.

\section{Methods}

This study will involve the concept of technology readiness on the product (TRL, IRL and SRL), will also involve technological readiness at manufacturing technologies (MRL). The Fig.1 below illustrates the schematic relationship between technological readiness assessments. The overall relationship between TRL, IRL, SRL and MRL will produce SRL ${ }^{+}$. 


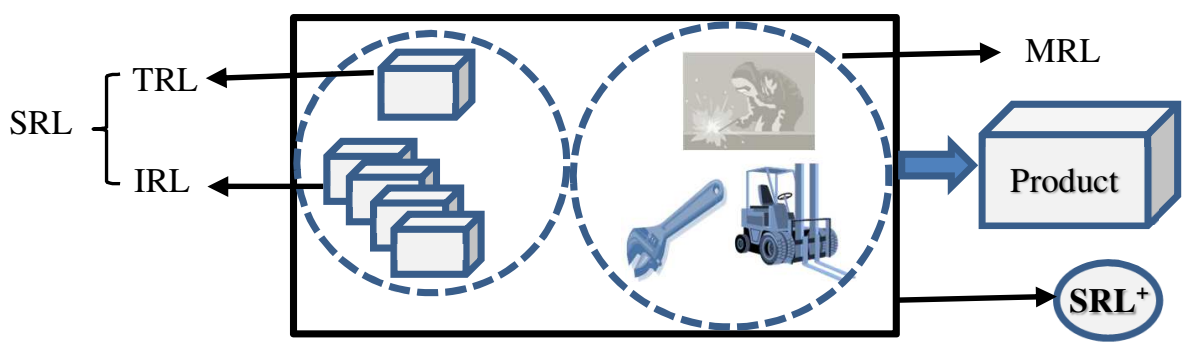

Fig. 1. Schematic relationship between TRL, IRL, MRL and SRL ${ }^{+}$

Table 1 demonstrates the comparison of the existing system technology assessments.

Table 1. The comparison of the existing system technology assessments

\begin{tabular}{|c|c|c|c|c|}
\hline $\begin{array}{c}\text { System } \\
\text { Technology } \\
\text { Assessment }\end{array}$ & TRL & IRL & SRL & MRL \\
\hline $\begin{array}{c}\text { The focus } \\
\text { of measure- } \\
\text { ment }\end{array}$ & $\begin{array}{l}\text { To measure } \\
\text { technology } \\
\text { components } \\
\text { or critical } \\
\text { systems in a } \\
\text { period of } \\
\text { time }[5,6]\end{array}$ & $\begin{array}{l}\text { To measure } \\
\text { the ability } \\
\text { of } \\
\text { technology } \\
\text { elements/ } \\
\text { interrelated } \\
\text { discrete } \\
\text { components } \\
{[5,6]}\end{array}$ & $\begin{array}{l}\text { To evaluate whole-system } \\
\text { development risk and to support } \\
\text { program acquisition decisions } \\
\text { [6] } \\
\text { SRLs mathematically combined } \\
\text { component TRL values with } \\
\text { system integration IRL and } \\
\text { created a separate measure of } \\
\text { system technical progress [7] }\end{array}$ & $\begin{array}{c}\text { To measure } \\
\text { technology } \\
\text { readiness } \\
\text { level of } \\
\text { production } \\
\text { facilities of } \\
\text { an industry } \\
{[8]}\end{array}$ \\
\hline $\begin{array}{c}\text { The level of } \\
\text { measurement }\end{array}$ & 9 levels & 9 levels & involves levels of TRL and of IRL. & 10 levels \\
\hline
\end{tabular}

\section{Result and discussion}

\subsection{Development of SRL (SRL')}

Several steps can be conducted to design the $\mathrm{SRL}^{+}$model.

- The first step is developing the function of the $\mathrm{SRL}^{+}$model. Early SRL involves two functions: TRL and IRL, while in $\mathrm{SRL}^{+}$the function of MRL is added. The SRL is then termed IMSRL (Incidence Matrix System Readiness Level). The IMSRL is defined as a novel method for calculating sub-system and whole-system readiness levels using an incidence matrix minimum-value approach [10].

- The second step is conducting computation using a development model that is $\mathrm{SRL}^{+}$.

- The third step is carrying out mathematical properties and $\mathrm{SRL}^{+}$readiness reversal. Both are adopted from SRL model testing $[9,10,12]$. The mathematical properties is used to help build mathematical frameworks for the further development of readiness metrics for systems and SoSs (System of Systems). Readiness reversal generates inaccurate system development assessments and encourages a system to a developmental phase before the system has demonstrated the required characteristics.

\subsubsection{The first step:}

The basic concepts of SRL involves 2 functions, namely TRL and IRL [8].

$$
S R L=f(T R L, I R L)=T R L \times I R L
$$


While $\mathrm{SRL}^{+}$adds MRL function becomes:

$$
S R L^{+}=f\{(T R L, I R L), M R L\}
$$

Based on the SRL metric developed by [11], SRL is formed by multiplying the normalized MRL, the TRL, and the mean of the normalized IRL in a scalar contraction (dot product)[11]. And to make the SRL metric by [11] is different from the basic concept from [8], so this article using the term of SRL plus or SRL ${ }^{+}$.

$$
S R L^{+}=(T R L \times I R L) \times M R L=S R L \times M R L
$$

where, TRL is a technological readiness of the measured component; IRL is a technological readiness of interconnected components; SRL is a technological readiness of the measured system; and MRL = technological readiness of an industrial manufacturing technologies.

SRL hereinafter called IMSRL (Incidence Matrix System Readiness Level), is described as follows:

$$
\begin{gathered}
I M S R L=\left[\min \left(I T R L_{\text {min }}\right)\right] \\
I T R L_{\text {min }}=\left[\min \left(\min \left(\left\{I R L_{i, j}^{T}>0\right\}_{i=1}^{m} x\left\{T R L^{T}\right\}\right)\right)\right]
\end{gathered}
$$

Where, IMSRL is a novel method for calculating sub-system and whole-system readiness levels using an incidence matrix minimum-value approach; and ITRL = IntegrationTechnology Readiness Level, which determines the relationship between TRL and IRL [10]. So:

$$
S R L^{+}=f\{(T R L, I R L), M R L\}=f\{I M S R L, M R L\}
$$

If the level scales on IRL and SRL are 1-9, then the MRL is 1-10, so it will be normalized to make it feasible.

\subsubsection{The second step:}

The computation is carried out using example in [10], as indicated in Fig. 2. The figure below gives the example of IMSRL assessment. Consider the general graph of Fig. 2 with three TRL component values $\{$ TRL $1=6$, TR $2=4$, TRL $3=8\}$ and five IRL edges $\{$ IRL $1->2=5$, IRL2$3=9$, IRL $1<->3=7$, IRL3 $->2=9$, IRL2->2=5 $\}$. The IRL edge set contains both undirected $\{$ IRL2-3 $=9\}$ and directed edges $\{$ IRL1->2=5, IRL1<->3=7, IRL3->2=9 $\}$, as well as a vertex loop at TRL2 $\{$ IRL2->2 $=5\}$.

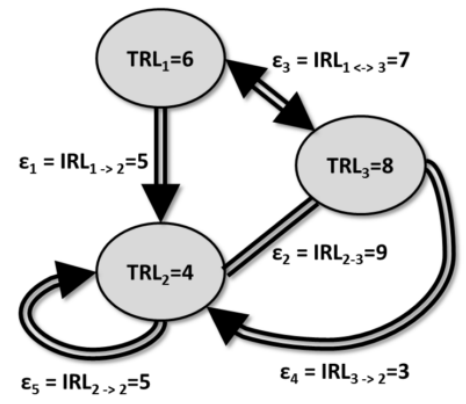

Fig. 2. An example of IMSRL assessment; adopted from [10] 
The following examples of IMSRL calculations taken from $[9,10]$ :

There are 3 TRL component values, namely TRL-1 $=6$, TRL-2 $=4$; TRL-3 $=8$.

There are 3 IRL connections, namely: IRL 1-2 = 5, IRL 2-3 = 9, IRL 1-3 = 7

$$
\begin{gathered}
T R L=\frac{1}{9}\left[\begin{array}{l}
6 \\
4 \\
8
\end{array}\right]=\left[\begin{array}{l}
0.67 \\
0.44 \\
0.89
\end{array}\right] ; I R L=\frac{1}{9}\left[\begin{array}{lll}
5 & 0 & 7 \\
5 & 9 & 0 \\
0 & 9 & 7
\end{array}\right]=\left[\begin{array}{ccc}
0.56 & 0 & 0.78 \\
0.56 & 0.44 & 0 \\
0 & 0.44 & 0.78
\end{array}\right] \\
I T R L_{\text {min }}=\left[\begin{array}{l}
0.44 \\
0.44 \\
0.44
\end{array}\right] ; I M S R L=\min \left[\begin{array}{l}
0.44 \\
0.44 \\
0.44
\end{array}\right]=0.44
\end{gathered}
$$

\subsubsection{The third step:}

The mathematical properties and $\mathrm{SRL}^{+}$readiness reversal are adopted from SRL model testing $[10,12]$. The mathematical properties is adopted through a testing on four model properties [12].

- Property \# 1: The ITRL $\mathrm{I}_{\mathrm{i}}$ and $\mathrm{SRL}^{+}$cannot exceed the maximum available value for TRL or IRL.

$$
S R L^{+}=\min (\min (\operatorname{IRL} x T R L) \leq 1
$$

- Property \# 2: raising TRL without changing other components will not decrease ITRL or $\mathrm{SRL}^{+}$values

- Property \# 3: The existence of new technology with TRL and IRL is equal to or greater than the initial SRL, then the new SRL will be greater or equal to the initial SRL.

- Property \# 4: ITRL component or subsystem does not exceed the maximum TRL or ITRL component or subsystem.

We use the example above and using Equation (6):

If $: \mathrm{SRL}^{+}=\mathrm{f}\{(\mathrm{TRL}, \mathrm{IRL}), \mathrm{MRL}\}=\mathrm{f}\{\mathrm{IMSRL}, \mathrm{MRL}\}$. Then:

$$
S R L^{+}=\min (I M S R L) \times\left(\frac{1}{10}\right) M R L
$$

- If $\mathrm{MRL}=3$, so: $\mathrm{SRL}^{+}=0.44 \times \frac{3}{10}=0.132(0.132 \leq 1)$; property 1 is fulfilled.

- If MRL is raised to 4, then: $\mathrm{SRL}^{+}=0.44 \times 4 / 10=0.44 \times 0.4=0.176(0.176>0.132)$; property 2 and 3 are fulfilled.

- $\quad$ ITRL $=0.44<\max$ TRL $=0.89$; property 4 is fulfilled.

Table 2 shows the acquisition stage for the value of a particular SRL which established

\begin{tabular}{|c|c|c|c|c|c|}
\hline & \multicolumn{5}{|c|}{ TRL/IRL Scale Value } \\
\hline & $\begin{array}{llll}1 & 2 & 3 & 4\end{array}$ & 5 & 7 & 8 & 9 \\
\hline $\begin{array}{l}\text { Acquisition } \\
\text { Phases }\end{array}$ & $\begin{array}{l}\text { Material } \\
\text { Solution } \\
\text { Analysis } \\
\text { (MSA) }\end{array}$ & $\begin{array}{c}\text { Technology } \\
\text { Demonstration } \\
\text { (TD) }\end{array}$ & $\begin{array}{c}\text { Engineering \& } \\
\text { Manufacturing } \\
\text { Development } \\
\text { (EMD) }\end{array}$ & $\begin{array}{l}\text { Production \& } \\
\text { Deployment } \\
\text { (P\&D) }\end{array}$ & $\begin{array}{l}\text { Operations } \\
\text { \& Support } \\
\text { (O\&S) }\end{array}$ \\
\hline $\begin{array}{c}\text { IMSRL Value } \\
\text { Range }\end{array}$ & {$[0.00,0.44]$} & {$[0.44,0.55]$} & {$[0.56 .0 .79]$} & {$[0.80,0.89]$} & {$[0.90,1.00]$} \\
\hline
\end{tabular}
according to the scale of the mapping SRL. This process is referred to as $\mathrm{SRL}^{+}$readiness reversal.

Table 2. IMSRL values; adopted from [10] 
This study defined the $\mathrm{SRL}^{+}$readiness reversal as a calculation of certain higher SRL values than certain TRL and IRL combinations that can be supported. By referring to the Table 2, then in the example : $\mathrm{SRL}^{+}=0.132$. This means the cluster is in the MSA phase. With a minimum value of TRL $=4$, then the system is still in the MSA phase.

\section{Conclusion}

The value of the four properties are fulfilled and confirmed that $\mathrm{SRL}^{+}$is a stable and mathematically robust model capable of assessing complex systems. Readiness reversal method is utilized as a method of $\mathrm{SRL}^{+}$computation evaluation [10]. It is clear from the method that the value of SRL${ }^{+}$will be higher than the values of TRL, IRL, and MRL which support it. In reference to table of SRL scale, the value of TRL=4, 6, 8; IRL = 5,7,9; IMSRL $=0.44$; and MRL $=3$, so the value of $\mathrm{SRL}^{+}$is 0.132 . It is meaning that the clusters are in phase of MSA. With TRL minimum value of 4 , the system remains in the phase of MSA. This indicates that $\mathrm{SRL}^{+}$model can be mathematically proven.

\section{References}

[1] D. Clausing, M. Holmes, Res. Manag. 53, 52-59 (2010)

[2] J.C. Mankins, Acta Astronaut, 65, 1216-1223 (2009)

[3] N. Azizian, T. Mazzuchi, S. Sarkani, D.F. Rico, Syst. Eng., 14, 410-425 (2011)

[4] C. Wei-gang, L. Wo-ye, G. Yan, H. Fei, Int. Conf. Manag. Sci. Eng. - Annu. Conf. Proc., 1993-1998 (2013)

[5] S. Peters, Prod. Eng., 9, 647-654 (2015)

[6] M.S. Seablom, L.A. Lemmerman, Int. Geosci. Remote Sens. Symp. 5646-9 (2012)

[7] A.E. Gudanowska, Bus. Theory Pract., 17, 243-250 (2016)

[8] W. Tan W, J. Ramirez-marquez, B. Sauser, Syst. Eng., 14, 279-293 (2011)

[9] M.A. London, T.H. Holzer, T.J. Eveleigh, S. Sarkani, J. Syst. Sci. Syst. Eng. 23, 377403 (2014)

[10] M.A. London, Evaluating System Readiness Level Reversal Characteristics Using Incidence Matrices, Dissertation (2015)

[11] S. Ross, Def. ARJ, 23, 248-273 (2016)

[12] E. Mcconkie, T.A. Mazzuchi, S. Sarkani, D. Marchette, Syst. Eng., 16, 391-400 (2013) 